nectionist alternative to symbol processing, concerns Jerome Feldman's 100-step rule. The brain can solve many difficult cognitive problems in half a second. If a neuron takes 5 milliseconds to perform one operation, then it should be possible to devise algorithms for solving the same problems that require only 100 steps. Although the SOAR program of the late Allen Newell respected this constraint, most AI programs take millions of steps; connectionist algorithms, by contrast, distribute the information over many simple processing units and work in parallel. The first-generation neural network models, however, were weakest where symbol processing is strongest, in representing relationships between abstract categories. The analysis of nonlinear networks as dynamical systems is still in its infancy and I suspect that the next generation of network models, based on spiking neurons, may provide additional computational abilities that may overcome this limitation.

The third debate reaches into the heart of AI and questions the need for representations at all. Rodney Brooks incorporates a hierarchy of reactive behaviours into walking machines that inhabit the Massachusetts Institute of Technology; the emphasis is on action selection rather than highly detailed sensory representations. Of course, as the control of actions becomes more sophisticated, the burden of intelligence is simply shifted from the sensory to the motor side. Franklin declares his own bias for a theory of intelligence based on an action-selection scheme, in which tasks are solved by a variety of specialized agents. These autonomous agents remind me of programs on the World Wide Web, such as 'spider' agents that seek out and catalogue information available at Web sites. If the digital computer served as a model of the mind for a generation of students in cognitive science, will the next generation be guided by their experience surfing on the Internet?

Artificial Minds is a readable guide to the evolution of ideas in artificial intelligence. It is intended for a general audience that already has some familiarity with symbolic AI and could be used, like a tour guide, to decide what areas of nouvelle AI to visit in greater depth. My only disappointment is that cognitive neuroscience, the science of real minds, plays only a small part in the book, perhaps because this field is of less interest to the author, whose background is in mathematics and computer science. New techniques for probing brains in action are uncovering unexpected insights into the organization of human minds. But that is another tour.

Terrence J. Sejnowski is at the Salk Institute, 10010 North Torrey Pines Road, La Jolla, California 92037, USA.

\section{Hard to swallow}

\section{Bruce Traill}

The Food System: A Guide. By Geoff Tansey and Tony Worsley. Earthscan: 1995. Pp. 259. £15.95 (pbk).

PERHAPS it is unfair for an economist to review this book. Economists are mostly of the view that markets are a good thing and that the 'invisible hand' provides a cheap and efficient mechanism for allocating resources and rewarding effort. Of course, we recognize that markets are not perfect and that in certain cases political intervention is needed to regulate or otherwise remedy market failure: markets may become monopolized, 'externalities' may exist that are not taken into account by producers or consumers (such as the environmental implications of intensive farming or food packaging) and consumers may have inadequate knowledge to make informed choices (over food safety or nutritional issues, for example). The economist's response is to identify precisely the source of the market failure and take the necessary corrective action (provided that the benefits of doing so outweigh the costs).

The authors of this book start from the opposite position, believing that the market mechanism is fundamentally flawed and cannot be trusted to perform even the simplest tasks. They therefore conclude that the food system should be thoroughly managed to achieve a set of food-policy goals: the equitable provision of a safe, secure, sustainable, sufficient and nutritious diet for all. It is hard to argue with such basic objectives, the real question of course being whether politicians, civil servants and (much favoured by the authors) publicinterest nongovernmental organizations (PINGOs, as opposed to BINGOs, business and industry NGOs) can do a better job than a lightly regulated market of telling businesses what food to produce, and where and how, and consumers what to eat.

The authors spend most of the book describing their interpretation of the way in which the food system works in the developed world (with examples primarily from the United Kingdom and Australia) and where it is going wrong. A short set of conclusions discusses "general approaches" to the development of food policies for a new millennium.

In the book's favour, it does provide a lot of facts on a very wide range of subjects from ecology ("food and the biosphere") and food-poisoning organisms, through industrial and retailing change, to advertising and consumer market segments and much more besides. The book is divided into three main parts, the first dealing with global issues: it describes world agriculture (and its harmful effects on the environment); gives a short economic history of the world (and how it has resulted in a system in which richcountry citizens over-consume processed foods while poor-country citizens starve); and reviews nutrition science, food safety and the psychology and sociology of consumer food choice (and why we are all overweight and consequently exploited by clever advertising agents over our fears of not being slim and beautiful).

The second part of the book describes the principal actors in the food chain and their interaction. It covers farmers and the effects of agricultural policies on farming practices and farm income distribution, and the growing scale and global nature of the (often multinational) corporations involved in trading agricultural commodities, manufacturing food, sourcing produce and retailing and catering. It is not by this stage in the book a surprise to find that the authors believe that consumers have too little power in the system and that small-scale local operations are preferable to largescale global ones.

Power is returned to as the main theme in the final part of the book dealing with what the authors term "food control" mechanisms. These are the use of science and technology, information and sophisticated management techniques by actors to gain control in the food chain, and the use of policy to regulate the power and determine the distribution of benefits among the actors. There is the familiar argument that large corporations influence the allocation of research funds and so control the direction of technical progress. They also pay for advertising foods (and drinks) that are nutritionally harmful, and fund foodrelated (mis)education in schools. To top it all off, policies that could moderate these effects are formulated today by civil servants with male-centred ideologies and, according to an Australian survey quoted, a "pseudo-religious belief in the market".

Derek Cooper, a presenter of the British radio series "The Food Programme", is quoted on the front cover as saying: "if you want to understand why the world feeds itself the way it does, you must read this book". Be warned that, although one can have sympathy with many of the points the authors make, and despite an impression that the authors are often trying to appear impartial, the understanding one is fed is not entirely balanced.

Bruce Traill is in the Food Economics Group, University of Reading, Reading RG6 GAR, UK. 